\title{
Validity of the Multidimensional Ethics Scale for a Sample of Thai Physicians
}

\author{
D.C. Malloy ${ }^{1,2}$, P. R. Sevigny ${ }^{3}$, T. Hadjistavropoulos ${ }^{2,3}$, Paholpak, S. ${ }^{4}$,
}

\begin{abstract}
Research in ethical decision-making has received considerable attention in the realm of the business community in the last three decades due in part to numerous high profile scandals (e.g., Enron). The medical community has been less engaged in this line of investigation as the primary scholar focus has been in biomedical as opposed to social science/humanities. However, recently researchers and their methods have been attracted to the medical field. The purpose of this paper is to explore whether an ethical decision-making measure prominent in the business literature can be applied to the medical contexts.
\end{abstract}

\section{Introduction}

Ethics in medicine has a profoundly long history from the early followers of Hippocrates to the disciples of Taoism and traditional Chinese medicine. However, it has not been until recently that a concerted effort has been made to study the decision-making behaviour of physicians (Malloy et al., 2008).

Much of the contemporary applied ethics research has focused upon the perceptions and practices of members of the business community (Cohen et al., 1996) with development and use of questionnaires to assess ethical judgement and ideology (Forsyth, 1980). Of the many instruments used to assess ethical decision-making in this context, the Multidimensional Ethics Scale (MES) developed by Reidenbach and Robin (1988) has received considerable attention. The purpose of this study was to determine if the MES was a viable instrument to be used in medical contexts.

\footnotetext{
${ }^{1}$ Faculty of Kinesiology \& Health Studies, University of Regina, Canada

${ }^{2}$ Centre on Aging and Health, University of Regina, Canada

${ }^{3}$ Department of Psychology, University of Regina, Canada

${ }^{4}$ Department of Psychiatry, Faculty of Medicine, Khon Kaen University, Thailand

Corresponding author:

Dr. D.C. Malloy

Room 109 Office of Research Services,

Research \& Innovation Centre,

University of Regina, Regina, SK, Canada, S4S 0A2, Email: David.Malloy@uregina.ca.
}

The MES was originally developed to assess ethical decision-making in business (Reidenbach \& Robin, 1988; 1990). To this end, 33 items were designed to tap into five ethical decision domains: Deontology, Utilitarianism, Relativism, Egoism, and Justice. Deontology considers ethical conduct to be duty-based in which the outcome of our actions are of secondary importance. Utilitarianism argues that the outcome is the primary goal of ethical conduct and the process one employs is of less immediate concern. Relativism purports that outcome and process are particular to the situation and that one must be flexible when deciding what is or is not ethical conduct (when in Rome do as the Romans do). Egoism is individually-based and directs each of us to pursue the greatest pleasure for ourselves as a means to seek the 'good'. Finally, justice has its roots in Aristotelian theory whereby equals ought to be treated equally.

Through the use of exploratory factor analysis (EFA), the number of items was eventually brought down to eight, measuring a total of three dimensions that combined to form the final version of the MES. The first dimension is Moral Equity, representing the notion of right and wrong is a second dimension that taps into social concepts learned through experience. The final dimension, Contractualism, represents the notion of obligation and social contract.

Although the scale, as developed by Reidenbach and Robin, consists of eight items divided over three dimensions (MES-8), it has been used in different variations since its inception. For example, using the same initial 
items as Reidenbach \& Robin (1990), but a different analytical approach, Hanson (1992) derived a 16-item scale comprising five dimensions. Cohen, et al. (1996) empirically derived a 12-item scale that clustered onto four dimensions. McMahon and Harvey's (2007) 10-item scale displayed little evidence of a multidimensional structure. The numerous iterations of this scale have rendered comparison of results across studies challenging.

Regardless of which version has been used, MES has been exclusively applied within a business context. Thus, to assess its applicability for use with a different population, it is important to test and validate the factor structure of the instrument in a sample drawn from a new population (Bollen, 1989, Byrne, Shavelson, \& Muthén, 1989). This study focuses on assessing the validity of the MES-8 in a medical context with physicians.

\section{Methods}

\section{Participants and Procedures}

Physicians in this study were participating in a larger investigation exploring the cross cultural influences on ethical decision making. This research was approved by the Research Ethics Board of the University of Regina, Canada and Khon Kaen University, Thailand. Eight hundred names were chosen at random from the national directory of physicians in Thailand. A total of 319 physicians participated in this study (39.9\% response rate). Seven scenarios were derived from ethical dilemmas identified by physicians during separate focus group sessions (Malloy et al, 2008 a description of the methodology; the scenarios are presented in Appendix A). To avoid participant burnout, four parallel questionnaire packets were compiled such that each participant completed two of seven scenarios. Packet A contained scenarios 1 and 2, packet B contained scenarios, 3 and 4 , packet $C$ contained scenarios 5 and 6 and packet $D$ contained scenarios 1 and 7 . Age and sex of the participants as well as the number of participants who completed the MES-8 per scenario can be found in Table 1.

Overall, $23.5 \%$ of the respondents indicated they were general practitioners. A cross section of specialties is also represented with physicians self-identifying 24 different areas of specialization. Nearly all physicians (98.4\%) completed their medical training in Thailand. In terms of religious affiliation, the vast majority of physicians (95.9\%) identified themselves as Buddhists.

\section{Translation}

When conducting cross-cultural research it is essential that the language used across cultures is equivalent. To minimize the impact of language differences the questionnaire underwent a translation and back-translation process (Sekaran, 1983). The MES and scenarios were originally compiled in Canada (English) and then translated by language experts in Thailand. Scenarios were then translated back into English by Canadian experts. The back translations were reviewed by the research team to ensure accuracy. While no translation is entirely error free, we believe this method minimizes the potential threats to the study's validity.

\section{Analyses}

The use of exploratory factor analysis was deemed appropriate for several reasons. First, as detailed previously, different factor structures have been found across studies (Cohen, et al., 1996; Hanson, 1992; McMahon \& Harvey, 2006). Second, to our knowledge this is the first study that has employed MES with a sample of physicians. Third, our sample was drawn from Thailand which is clearly a different cultural context from the United States where MES was developed. Fourth, confirmatory factor analysis was not advisable due to the low number of items comprising two of the subscales of MES. At least three items per subscale are needed for the validation of a multidimensional scale, (Bollen, 1989; Marsh \& Hau, 1999), while MES contains two subscales consisting of merely two items. Thus, seven EFAs, (one for each scenario) were conducted to assess whether the original factor structure (Reidenbach \& Robin, 1990) held for a sample of physicians. Many of the earlier factors analytic studies of the MES employed principal components analysis (PCA) and varimax rotation PCA strictly speaking is a data reduction technique. Since our aim was to explore the underlying factor structure of the already distilled 8-item MES, maximum likelihood extraction is well suited for this purpose (Costello \& Osbourne, 2005). Since recent studies have found the MES factors to be correlated (McMahon \& Harvey, 2007; Nguyen \& Biderman, 2008) direct oblimin oblique rotation, was employed.

Similar to research by Reidenbach, Robin, and Dawson (1991), multiple regressions were conducted to assess the relative impact of the three dimensions on a measure of ethical evaluation (i.e., to assess the scale's level of 
criterion validity). To this end, a single item measuring whether the presented scenario was deemed ethical or unethical on a 7-point Likert scale was included as the outcome variable. Seven multiple regressions, using the enter method, were conducted; one for each scenario using the data obtained from the physicians.

\section{Results}

Bartlett's test of sphericity was significant for all seven EFA's $(p<.001)$ and the KMO measure of sampling adequacy was satisfactory (Norusis, 1988; see Table 2). The EFAs show some varying results, although four out of seven scenarios (i.e., scenarios 1 , 2,4 , and 6), all items are clustered into one overall factor. However, there is some support for the existence of a two-factor structure as well. When two factors were identified (scenario seven), the first two factors were combined (Moral Equity and Relativism), while the two items intent to measure Contractualism form to one factor. However, in this case the combined factor is by far the most important factor (i.e., it explains the most variance). Also, scenarios 3 and 5 showed multiple cross loadings and displayed no clearly interpretable factor solution.

The results of the EFAs suggested the existence of a one-factor solution, or possibly a combination of the first two factors (Moral Equity the Relativism) of the original MES-8. The latter was supported by high inter-factor correlations between the two factors. All correlations between these factors are 0.7 or above (See Table 3). This supports the notion that the two factors are measuring, to a large extent, the same concept. Correlations between Moral Equity and Constructualism or between Relativism and Constructualism did not exceed 0.7. However, all correlations were statistically significant at $p<0.05$, suggesting that all three factors are strongly related to each other.

Results of the multiple regressions showed that the MES-8 is a significant predictor of the univariate measure of ethics conducted with a sample consisting of physicians. The scale explained between $43 \%$ and $62 \%$ of the variance in the ethical judgement measure.

The results also showed consistently that Moral Equity was the most important predictor of the univariate ethics measure. In all cases, Moral Equity had the largest standardized Beta, indicating its relative importance.

Combining the results of the EFA and the multiple regressions, it can be assumed that a large amount of variance is shared between at least the first two subscales (Moral Equity and Relativism), which can be combined into one subscale. Also, Contractualism can be considered a part of one overarching factor, combining all three original subscales. The results of the multiple regressions showed that if Contractualism was regarded as a separate factor, its impact on the univariate ethics measure was small and in most cases not significant.

Table 1: Participant Sample Size and Mean Age (SD) Divided by Sex, and Scenario

\begin{tabular}{lcccc}
\hline & \multicolumn{2}{c}{ Male } & \multicolumn{2}{c}{ Female } \\
\hline & $\mathrm{N}$ & Mean age (SD) & $\mathrm{N}$ & Mean age (SD) \\
\cline { 2 - 5 } Scenario 1 & 87 & $44.3(10.9)$ & 67 & $39.7(11.6)$ \\
Scenario 2 & 43 & $43.3(11.2)$ & 36 & $41.9(12.2)$ \\
Scenario 3 & 45 & $46.5(11.4)$ & 39 & $41.2(12.6)$ \\
Scenario 4 & 45 & $46.5(11.4)$ & 39 & $41.2(12.6)$ \\
Scenario 5 & 44 & $43.8(9.0)$ & 37 & $39.0(10.0)$ \\
Scenario 6 & 44 & $43.8(9.0)$ & 37 & $39.0(10.0)$ \\
Scenario 7 & 44 & $45.2(10.7)$ & 31 & $37.0(10.2)$ \\
\hline
\end{tabular}


Table 2: Factor Solutions for 8-Item MES in Seven Scenarios

\begin{tabular}{|c|c|c|c|c|c|c|c|c|c|c|}
\hline \multirow{3}{*}{$\begin{array}{l}\text { KMO measure } \\
\text { Factor ( } \% \text { of variance) }\end{array}$} & \multirow{3}{*}{$\begin{array}{c}\text { Sc. 1 } \\
.88 \\
\begin{array}{c}F 1^{*} \\
(67 \%)\end{array}\end{array}$} & \multirow{3}{*}{$\begin{array}{c}\text { Sc. } 2 \\
.91 \\
\begin{array}{c}F 1^{*} \\
(68 \%)\end{array}\end{array}$} & \multirow{2}{*}{\multicolumn{2}{|c|}{$\begin{array}{c}\text { Sc. } 3 \\
.84\end{array}$}} & \multirow{3}{*}{$\begin{array}{c}\text { Sc. } 4 \\
.88 \\
\begin{array}{c}F^{*} \\
(70 \%)\end{array}\end{array}$} & \multirow{2}{*}{\multicolumn{2}{|c|}{$\begin{array}{c}\text { Sc. } 5 \\
.70\end{array}$}} & \multirow{3}{*}{$\begin{array}{c}\text { Sc. } 6 \\
.86 \\
\begin{array}{c}F 1^{*} \\
(61 \%)\end{array}\end{array}$} & \multirow{2}{*}{\multicolumn{2}{|c|}{$\begin{array}{c}\text { Sc. } 7 \\
.87\end{array}$}} \\
\hline & & & & & & & & & & \\
\hline & & & $\begin{array}{c}\mathrm{F} 1 \\
(58 \%)\end{array}$ & $\begin{array}{l}F 2 \\
(8 \%)\end{array}$ & & $\begin{array}{c}\mathrm{F} 1 \\
(34 \%)\end{array}$ & $\begin{array}{c}\mathrm{F} 2 \\
(23 \%)\end{array}$ & & $\begin{array}{c}F 1 \\
(62 \%)\end{array}$ & $\begin{array}{c}F 2 \\
(12 \%)\end{array}$ \\
\hline Fair - Unfair & .94 & .93 & .94 & .70 & .93 & .83 & .43 & .79 & .91 & -.53 \\
\hline Just - Unjust & .92 & .90 & .89 & .62 & .86 & 1.00 & .49 & .83 & .94 & -.45 \\
\hline $\begin{array}{l}\text { Morally right }- \text { Not } \\
\text { morally right }\end{array}$ & .86 & .86 & .69 & .72 & .84 & .53 & .70 & .81 & .86 & \\
\hline $\begin{array}{l}\text { Acceptable - } \\
\text { Unacceptable to my } \\
\text { family }\end{array}$ & .85 & .83 & .78 & .85 & .90 & .41 & .71 & .93 & .82 & \\
\hline $\begin{array}{l}\text { Culturally acceptable - } \\
\text { Unacceptable }\end{array}$ & .90 & .91 & .60 & .86 & .92 & .56 & .80 & .92 & .86 & \\
\hline $\begin{array}{l}\text { Traditionally acceptable - } \\
\text { Unacceptable }\end{array}$ & .87 & .87 & .60 & .90 & .86 & & .94 & .87 & .85 & \\
\hline $\begin{array}{l}\text { Violates - Does not } \\
\text { violate an unwritten } \\
\text { contract }\end{array}$ & $\underline{-.52}$ & -.67 & -.42 & & $\underline{-.63}$ & -.42 & &.- .54 & & .75 \\
\hline $\begin{array}{l}\text { Violates - Does not } \\
\text { violate an unspoken } \\
\text { promise }\end{array}$ & $\underline{-.60}$ & $\underline{-.54}$ & -.67 & -.46 & $\underline{-.69}$ & & &.- .40 & -.45 & .89 \\
\hline
\end{tabular}

Note. * Results from component matrix

Table 3: Correlations Between the subscales of the MES for Seven Different Scenarios

\begin{tabular}{|c|c|c|c|c|c|}
\hline & & $M(S D)$ & ME & Rel. & Con. \\
\hline Scenario 1 & $\mathrm{ME}$ & $3.0(1.6)$ & & & \\
\hline$(\mathrm{N}=154)$ & $\begin{array}{l}\text { Rel. } \\
\text { Con. }\end{array}$ & $\begin{array}{l}3.2(1.6) \\
4.4(1.5)\end{array}$ & $\begin{array}{l}.86 \\
-.59\end{array}$ & -.55 & \\
\hline $\begin{array}{r}\text { Scenario } 2 \\
(N=79)\end{array}$ & $\begin{array}{l}\text { ME } \\
\text { Rel. } \\
\text { Con. }\end{array}$ & $\begin{array}{l}3.3(1.7) \\
3.5(1.7) \\
4.7(1.4)\end{array}$ & $\begin{array}{r}.89 \\
-.70\end{array}$ & -.66 & \\
\hline $\begin{array}{r}\text { Scenario } 3 \\
(\mathrm{~N}=84)\end{array}$ & $\begin{array}{l}\text { ME } \\
\text { Rel. } \\
\text { Con. }\end{array}$ & $\begin{array}{l}4.2(1.3) \\
3.3(1.3) \\
3.8(1.3)\end{array}$ & $\begin{array}{l}.76 \\
-.59\end{array}$ & -.38 & \\
\hline $\begin{array}{r}\text { Scenario } 4 \\
(\mathrm{~N}=84)\end{array}$ & $\begin{array}{l}\text { ME } \\
\text { Rel. } \\
\text { Con. }\end{array}$ & $\begin{array}{l}3.2(1.4) \\
3.0(1.4) \\
4.4(1.5)\end{array}$ & $\begin{array}{l}.86 \\
-.70\end{array}$ & -.59 & \\
\hline $\begin{array}{r}\text { Scenario } 5 \\
\quad(N=81)\end{array}$ & $\begin{array}{l}\text { ME } \\
\text { Rel. } \\
\text { Con. }\end{array}$ & $\begin{array}{l}4.2(1.4) \\
3.8(1.6) \\
3.3(1.4)\end{array}$ & $\begin{array}{l}.70 \\
-.33\end{array}$ & -.22 & \\
\hline $\begin{array}{r}\text { Scenario } 6 \\
(N=81)\end{array}$ & $\begin{array}{l}\text { ME } \\
\text { Rel. } \\
\text { Con. }\end{array}$ & $\begin{array}{l}3.3(1.4) \\
3.3(1.5) \\
4.3(1.4)\end{array}$ & $\begin{array}{l}.84 \\
-.53\end{array}$ & -.48 & \\
\hline $\begin{array}{r}\text { Scenario } 7 \\
(N=75)\end{array}$ & $\begin{array}{l}\text { ME } \\
\text { Rel. } \\
\text { Con. }\end{array}$ & $\begin{array}{l}3.5(1.5) \\
3.4(1.4) \\
4.2(1.4)\end{array}$ & $\begin{array}{r}.86 \\
-.43\end{array}$ & -.37 & \\
\hline
\end{tabular}

Note. * All correlations were significant at $p<.05 ; \mathrm{ME}=$ Moral Equity, Rel.=Relativism, Con.=Contractualism 


\section{Discussion}

The purpose of this study was to assess the validity of the MES- 8 when completed by a sample of physicians. Our results did not support the original three-factor structure of the MES- 8 as developed by Reidenbach and Robin (1990), but rather a one-factor solution, and to a lesser extent a two-factor solution in which Moral Equity and Relativism were combined. Four out of the seven scenarios were used and provided support for the existence of one dominating factor. This is consistent with the findings of other researchers who found weak evidence for the multidimensional structure of the MES (McMahon \& Harvey, 2007; Nguyen \& Biderman, 2008; Tansey, Brown, et al., 1994). Reidenbach and Robin (1990) suggest that single factor findings may reflect a construct such as ethical judgment is being tapped that is characterized by overlapping ethical philosophies. Indeed, the results of our regression analyses found that the MES 8 was a strong predictor of the ethical judgement of Thai physicians. A two-factor solution similar to that found in the present study was also observed by Reidenbach et al. (1991).

Among other suggestions to explain the existence of a two-factor solution, the authors mentioned the natural relationship expected between what people perceive to be culturally acceptable and what is fair or just. If the meaning of fairness is closely related to what is deemed culturally acceptable, the two involved subscales should be closely related. In Thailand, Buddhism is the dominant religion, there may exist a more ambiguous sense of justice that would incorporate what is culturally acceptable. The ultimate aim of Buddhism is non-violence, there may be a broader acceptance of varying cultural paths leading to the end. For example, the Itivuttaka states that "all the means that can be used as bases for right action are not worth the sixteenth part of the emancipation of the heart through love. This takes all the others up into itself, outshining them in glory" (Hooks, 2007, p. 41). In the current exploratory study, the factor structure of the MES 8 was not invariant across the seven scenarios employed. This is consistent with recent studies by McMahon and Harvey (2007) and Nguyen and Biderman (2008) who found that scenario based factors played a significant role in understanding their MES data. It is important to note that in the present study, we used a grounded approach to scenario selection, to ensure that the ethical dilemmas articulated in each scenario were salient to physicians.

Our scenarios were derived from focus group sessions in which physicians were asked to describe their most commonly encountered ethical dilemmas (see Malloy et al., 2008). As This study, did not intentionally vary the presented situations based on any particular ethical principle or moral dimension. However, given the results found in this initial study, follow up investigations could vary and assess scenario based factors in a systematic way.

\section{Conclusion}

In conclusion, for a sample of physicians the MES-8 used in this study was dominated by one general factor. Even though the existence of Contractualism as a separate dimension has been acknowledged in this study as well as previous studies, its usefulness is limited due to the fact that it is comprised of only two items (Bollen, 1989). Furthermore, compared to the combined subscale of Moral Equity and Relativism, Contractualism has little power on predicting ethical judgment. The results of our study mirror those who have used the MES-8 within a business context. The MES- 8 is seen as a valid instrument in assessing the ethical decision making of physicians.

\section{References}

Bollen, K. A. (1989) Structural equations with latent variables, New York: John Wiley \& Sons.

Byrne, B. M., Shavelson, R. S. \& Muthén, B.(1989). Testing for the Equivalence of Factor Covariance and Mean Structures: the Issue of Partial Measurement Invariance, Psychological Bulletin, 105, pp. 456-466.

Cohen, J. R., Pant, L., W., \& Sharp, D. J. (1996) Measuring the ethical awareness and ethical orientation of Canadian auditors, Behavioral Research in Accounting, 8 (Supp) pp. 98-119.

Costello, A. B. \& Osborne, J. (2005) Best practices in exploratory factor analysis: four recommendations for getting the most from your analysis, Practical Assessment Research \& Evaluation, 10, 7 [Online] Available at http://pareonline.net/getvn.asp?v=10\&n=7 [Accessed 11 June 2011]

Forsyth, D. (1980) A taxonomy of ethical ideologies, Journal of Personality and Social Psychology, 39, pp. 175-184. 
Hansen, Randall S. (1992) A Multidimensional Scale for Measuring Business Ethics: A Purification and Refinement, Journal of Business Ethics,11, pp. 523-534.

Hooks, B. (2007). Creating a culture of love. In McLeod, M (Ed.) The Best Buddhist Writing, Boston: Shambala, pp. 40-49.

Malloy, D.C. Williams, J., Hadjistavropoulos, T., Krishnan, B., Jeyaraj M. Fahey McCarthy, E., Murakami M., Paholpak, S. Mafukidze, J. \& Hillis, B. (2008) Ethical decision-making about older adults and moral intensity: An international study of physicians, Journal of Medical Ethics, 34, pp. 285-296.

Marsh, H. W., \& Hau, K. T. (1999) Confirmatory factor analysis: Strategies for small sample sizes. In Hoyle, R.H. (Ed.), Structural equation modeling with small sample sizes, Newbury, CA,. Sage. (pp 251-306).

McMahon, J. M., \& Harvey, R. J. (2007) Psychometric properties of the ReidenbachRobin Multidimensional Ethics Scale, Journal of Business Ethics, 72, pp. 27-39.

Nguyen, N. T. \& Biderman, M. D. (2008) Studying ethical judgements and behavioural intentions using structural equations: evidence from the multidimensional ethics scale. Journal of Business Ethics, 83, pp. 627-640.
Norusis, M. J. (1988) SPSS/PC+ Advanced Statistics_V2.0 SPSS Inc.

Reidenbach, R. E., \& Robin, D. P. (1988) Some initial steps toward improving the measurement of ethical evaluations of marketing activities. Journal of Business Ethics, 7, pp. 871-879.

Reidenbach, R. E., \& Robin, D. P. (1990) Toward the development of a multidimensional scale for improving evaluations of business ethics, Journal of Business Ethics, 9, pp. 639-653.

Reidenbach, R. E., \& Robin, D. P., \& Dawson, L. (1991) An application and extension of a multidimensional ethics scale to selected marketing practices and marketing groups, Journal of the Academy of Marketing Science 19, pp. 83-92.

Tansey, R., Brown, G., Hyman M. R., \& Dawson, Jr, L. E., (1994) Personal moral philosophies and the moral judgments of salespeople. Journal of Personal Selling and Sales Manager, 14, pp. 59-75. 


\section{Appendix A: The Seven Scenarios}

Scenario 1: Quality of Life - Level of Treatment

Mrs. $X$ is an 85-year-old woman with terminal cancer and in significant pain. She is not expected to live more than 30 days. The attending physician realizes that to provide her with adequate pain relief, the administration of an increased dose of morphine may result in further complications that may hasten her death. Without an increase in the dosage of her medication she will perhaps live an additional month yet suffer profoundly.

Action: The physician increases the dosage of morphine.

\section{Scenario 2: Competence}

Mr. O. is a 73-year-old retired executive who has begun to show signs of early onset of dementia. His wife reports that he is getting lost while driving his car in the city in which he has lived all his life and often loses his car after parking for short periods of time. Mr. O. vehemently denies that he has memory issues and diverts blame to improper placement of street signs. Following testing that confirms dementia, Dr. M. must decide whether or not Mr. O. is a driving hazard due to his declining mental faculties.

Action: Dr. M calls the motor vehicle department to rescind Mr. O's license to drive.

\section{Scenario 3: Family Issues}

Mrs. E, a 93 year-old former nurse, is terminally ill with colon cancer, is in considerable pain, and wishes to die. Her daughter, Mrs. D who has been caring for her, accepts the impending death and is prepared to do everything she can to let her mother pass away in peace. Mr. E, the son, who not seen his mother in 3 years, insists that everything possible is done to continue his mother's life and threatened legal action if the extraordinary measures were not carried out.

Action: The attending physician indicated to the staff that Mrs. E should continue to receive pain medication and all other interventions to remain passive.

\section{Scenario 4: Disclosure}

Mr. $\mathrm{R}$ has brought his 67 -year-father to the physician's office to receive the results of tests performed earlier in the year - early onset of dementia is suspected. Before taking his father into the examining room, Mr. R speaks to the physician privately and requests that if there is any bad news (i.e., confirmed dementia) that his father not be informed because the news will be devastating to him and it is ultimately a family obligation.

Action: The physician does not tell the patient that he is developing dementia.

Scenario 5: Health Care System

Mr. V. is an 83-year-old patient who suffers from trigeminal neuralgia. He has been prescribed neurontin - a relatively new and expensive medication that will significantly reduce the chronic pain that he experiences. The cost of continuing treatment is considerably high for his only son to bear. His son requests that another less expensive, over the counter medicine (possibly much less effective) drug be prescribed to his father.

Action: The physician changes the prescription to the less expensive drug. 
Scenario 6: Physician Variables

A 78-year-woman suffering severe pain due to terminal cancer has an acute heart attack and is rushed to emergency. She has provided the hospital with a Do Not Resuscitate order. The emergency doctor is a devout Christian and does not believe in concept of DNR. He believes God gave him the gift of saving lives and thus his duty is to do all he can to serve God in this manner - no exceptions.

Action: The physician ignores the DNR and brings the patient back to life.

Scenario 7: Witnessing Inappropriate Treatment

Dr. B works in a government funded palliative care home. This institution is profoundly under-funded and as a result under-staffed. Many patients suffer from dementia and are prone to wandering around in the compound and often "escape". In order to prevent residents from leaving their room, restraints have been used. However, recently the media reported on this practice and a public outcry ensued. Despite her reluctance to use restraints, Dr. B realized that the patients had to be confined for their own good.

Action: Dr. B began sedating the more active patients to limit their mobility

\section{Notes}

Concerning the choice of an EFA over a CFA: A CFA was not possible due to the low number of items per subscale. Bollen (1989) recommends not using subscales with two items in a CFA. A case can be made that, because the MES has been used in different variations since it has been introduced, an EFA is legitimate.

Gorsuch (1983, p.332) recommends a minimum subject to item ratio of at least 5:1 in EFA, but also notes that higher ratios are generally better. On the other hand, Nunnally $(1978$, p. 421) recommends that the subject to item ratio for exploratory factor analysis should be at least 10:1.

Tansey et al. (1994):

Next, to check the dimensionality of Forsyth's taxonomy, a maximum likelihood factor analysis of his EPQ items was done (Gorsuch 1983; Norusis 1990); when trying to determine latent structure, Cureton and D'Agostino (1983) recommend a maximum likelihood factor analysis over a principal components factor analysis.

Cui et al. (2005):

First, Forsyth's (1980) two-dimension (Idealism and Relativism) ethical positioning scale was tested through CFA with LISREL 8.54 (Jöreskog \& Sörbom, 2000) for its applicability in each of the five different socio-cultural contexts. This also served as the precursor to testing cross-cultural measurement equivalence of the scale at a later stage because the scale should be valid for each sample before further test of cross-cultural invariance of the scale simultaneously across the five samples (Bollen, 1989; Byrne et al., 1989; Steenkamp \& Baumgartner, 1998). 